\title{
Editorial: Acoustical Impact of Ships and Harbors: Airborne and Underwater N\&V Pollution
}

\author{
Davide Borelli $^{1 *}$ and Tomaso Gaggero ${ }^{2 *}$ \\ ${ }^{1}$ DIME, Università degli Studi di Genova, Genoa, Italy, ${ }^{2}$ DITEN, Università degli Studi di Genova, Genoa, Italy
}

Keywords: ship noise, underwater radiated noise, maritime acoustics, animal bioacoustics, sound propagation

\author{
Editorial on the Research Topic
}

\section{Acoustical Impact of Ships and Harbors: Airborne and Underwater N\&V Pollution}

OPEN ACCESS

Edited by:

Eugen Victor Cristian Rusu,

Dunarea de Jos University, Romania

Reviewed by:

Nikolaos Kourogenis,

University of Piraeus, Greece

*Correspondence:

Davide Borelli

davide.borelli@unige.it

Tomaso Gaggero

tomaso.gaggero@unige.it

Specialty section:

This article was submitted to

Ocean Engineering, Technology, and

Solutions for the Blue Economy,

a section of the journal

Frontiers in Marine Science

Received: 30 December 2017

Accepted: 26 February 2018

Published: 16 March 2018

Citation:

Borelli D and Gaggero T (2018)

Editorial: Acoustical Impact of Ships

and Harbors: Airborne and

Underwater N\&V Pollution.

Front. Mar. Sci. 5:83.

doi: 10.3389/fmars.2018.00083
Aim of this Frontiers research topic is to analyse the different aspects of the impact of noise emitted by human activities and ships in particular. As ships have the peculiarity of operating at the interface between two fluids (air and water), noise generation takes place both in air and underwater, involving two different families of sources, propagation paths, and receivers. As regards airborne noise, sources are represented by the funnels, air intakes, and discharges and in general all the openings that put in communication the inside of the ship with the surrounding environment. The receivers are the inhabitants of port areas or channels with intense ship traffic. For what concerns ships underwater radiated noise, main noise sources are the propellers and the engines. While noise coming from the engines features a series of energy transformations, as vibrations are transmitted to the hull that radiates noise into water, the propeller is a much more efficient noise source which generates noise directly inside the water, especially when cavitation phenomena occurs. The widespread shipping traffic is responsible for a diffused broadband increase in the noise levels, while other noise sources such as air guns and military sonars generate very high level impulsive sounds. Receivers affected by underwater noise are potentially all the species living in the oceans, but attention is mainly focused on the consequences of noise on marine mammals. The effects on those species can range from temporary to permanent hearing losses or even death for high power noise sources to behavioral changes and communication problems for broadband diffused sources like shipping.

The normative framework development and the scientific studies in both fields of ship noise emissions (airborne and waterborne) featured a strong increase in the last decade. For what concerns the airborne noise, albeit ships, as noise sources, present characteristics which are similar to other typical transport systems (such as road vehicles, trains, etc.) when moving, and can be treated as an industrial plant if in a stationary situation, at the moment no instruments nor standards to specifically characterize, assess, and control this kind of noise are available. On the other hand, the human perception of noise and noise exposure consequences have been deeply studied. On the contrary, standards for the measurements of underwater noise from ships are already available, and some voluntary class notations to certify the low noise emission for ships have been issued by most of the classification societies taking advantage of the experience gained in the naval field. A lack of knowledge is in fact present as regards the impact that noise has on marine mammals. To this aim, the focus of the research is the assessment of the noise footprint of human activities both numerically, by means of models, and experimentally, by means of infield measurements. To reach this goal, a deeper knowledge of all the elements of the noise chain (source, transmission path, and receiver) is necessary. 
As regards the ship characterization as an underwater noise source, Karasalo et al. presented a study to estimate the noise source spectra of ships based on long term measurements in the Baltic sea. Data from over 2000 close-by passages, recorded during 3 months were used. A procedure for ship source spectra estimation was presented based on: sound recordings by a single hydrophone placed close to a shipping line; Automatic Identification System data to localize ships and gain information of their operative conditions and a model to estimate sound propagation. The acquired data were compared with source models available in literature, finding a good agreement between models and measurements for frequencies higher than $200 \mathrm{~Hz}$. Such kind of study is particularly important as very few data regarding commercial vessels underwater noise emissions are available in literature and it is extremely difficult and expensive to carry out ad-hoc measurements.

Concerning sound transmission at sea, van der Schaar et al. presented a study on noise propagation in the Arctic. The study took advantage of seismic surveys carried out by Statoil is summer 2013. Two different recorders were installed in the Greenland Sea, allowing the estimation of propagation losses acting on sound emitted by the air guns. The seismic surveys were carried out at distances ranging from 50 to $300 \mathrm{~km}$, and around 10,000 shots were detected and analyzed. Results showed that it is difficult to find a unique " $\log (\mathrm{R})$ " transmission loss law. Studying anthropogenic sound propagation in the Arctic is particularly important because anthropogenic actives are rapidly increasing in an uncontaminated environment which is more vulnerable. Moreover, the presence of ice influences sound transmission allowing the tuning of mathematical models.

As regards the effects on cetacenas, Parsons reviewed the problem of military sonars and their impact on mass strandings. The study underlines that there is a high level of uncertainity in this particular issue of marine science, and that there is a need for precaution due to several factors, e.g., the difficulty of finding and seeing strandings eve if they occur or the fact that most cetaceans sink upon death, making injury, or mortality at sea caused by noise unlikely to be observed. The suggestion is that all navies should implement best practices, effective monitoring, and mitigation measures, as well as the governments need to develop criteria for assessing and investigate atypical mass strandings.

Again, concerning cetaceans, Marley et al. analyzed the underwater soundscape of bottlenose dolphins habitat within the Swan-Canning River system in Western Australia. In this highly urbanized estuary in Perth, acoustical data were recorded and analyzed across 8 years. Among the multiple sound sources, the two most prevalent ones were vessels traffic and snapping shrimps. The analysis was carried out taking into account both spatial and temporal variations, and showed that vessels noise was the most disruptive sound, since its peculiar spectral and temporal characteristics tend to overlap and likely mask dolphin whistles, thus influencing their behavior.

This Frontier research topic represented an excellent opportunity for researchers to publish original works dealing with the impact of anthropogenic noise on the marine fauna. The published papers covered all the main aspects of the problem presenting studies regarding the assessment of noise effects by air guns and sonars on cetaceans, ship characterization as a source of underwater noise and noise propagation in an extreme environment such as the Arctic region.

\section{AUTHOR CONTRIBUTIONS}

All authors listed have made a substantial, direct and intellectual contribution to the work, and approved it for publication.

Conflict of Interest Statement: The authors declare that the research was conducted in the absence of any commercial or financial relationships that could be construed as a potential conflict of interest.

Copyright (c) 2018 Borelli and Gaggero. This is an open-access article distributed under the terms of the Creative Commons Attribution License (CC BY). The use, distribution or reproduction in other forums is permitted, provided the original author(s) and the copyright owner are credited and that the original publication in this journal is cited, in accordance with accepted academic practice. No use, distribution or reproduction is permitted which does not comply with these terms. 